\title{
A multifrequency and multisensor approach for the study and the restoration of monuments: the case of the Cathedral of Matera
}

\author{
N. Masini ${ }^{1}$, R. Persico ${ }^{1}$, A. Guida ${ }^{2}$, and A. Pagliuca ${ }^{3}$ \\ ${ }^{1}$ CNR-IBAM (Istituto per i Beni Archeologici e Monumentali), C.da S. Loja 85050 Tito Scalo (PZ), Italy \\ ${ }^{2}$ DAPIT, University of Basilicata, Potenza, Italy \\ ${ }^{3}$ Polytechnic of Bari, Bari, Italy
}

Received: 4 July 2008 - Revised: 14 October 2008 - Accepted: 3 November 2008 - Published: 14 November 2008

\begin{abstract}
In this paper we propose an integrated approach to diagnostic prospecting applied to the cathedral of Matera, in Southern Italy. In particular, we have performed both an ultrasonic tomography and a high frequency GPR prospecting on some pillars of the Church to investigate about possible structural yielding and a GPR prospecting at lower frequencies on the floor, where also a linear inversion algorithm has been applied to the data.
\end{abstract}

\section{Introduction}

The preservation of artistic and architectural heritage represents a bench mark of the cultural development of a society. To this end it is necessary to preserve both the material components and the knowledge of those values (historical, artistic, symbolical etc.) which are intangible aspects of the cultural heritage.

These two scopes can be reached by means of a multidisciplinary and interdisciplinary approach where non-destructive testing (NDT) provide a significant source of information on materials, state of conservation and aspects related to building history.

In particular, some case histories (Binda et al., 2003; Masini et al., 2007) show how complex it is to design the repairing interventions on historic stone masonry buildings. Most of them are characterized by load bearing structures which are highly inhomogeneous and this makes the structural modelling very difficult. For this reason, any repairing work needs the knowledge of the technique of construction and the characterization of the state of conservation of the manufactured article, with particular reference to voids, cracks and decay. To do this, in the past the only

Correspondence to: N. Masini

(n.masini@ibam.cnr.it) way was based on destructive survey through coring or local demolition.

Fortunately, nowadays an increased awareness of the cultural value and the brittleness of artefacts and monuments to be restored often prevent from further destructive investigations. This has favoured the use of non-destructive tests (NDT) as ground penetrating radar (GPR), sonic and ultrasonic tests.

As is well known, the techniques are based on different principles because the probing signals have different physical origin: stress waves for sonic and ultrasonic tests and Electromagnetic (EM) waves in the case of radar. The theoretical capabilities and limitations of the techniques are strictly related to the frequency band of the signals.

The frequency is related both to the resolution and to the rate of energy absorption, thus limiting the size of the building element that can be tested and characterized. Therefore, the attenuation of the signal and the resolution requirements have both to be considered in order to choose the optimal frequency band.

Moreover, with regard to the stress waves, the band can be meaningfully influenced by the characteristics of the surface materials, and the presence of a thick plaster can filter out the highest frequencies of the radiated band. This reduces the resolution and the capability to detect the inner morphology of masonry structures in detail with ultrasonic waves. In such situation the radar tests show some advantages.

In this paper we present the results of integrated NDT (GPR-ultrasonic) performed in the Cathedral of Matera, in order to answer to needs of the conservation and questions of the archaeological research.

The paper is organized as follows: in Sect. 2 the case history of the cathedral of Matera is described. In Sect. 3 the investigation and the processing are summarized and, finally, in Sect. 4 conclusions follow.

Published by Copernicus Publications on behalf of the European Geosciences Union. 


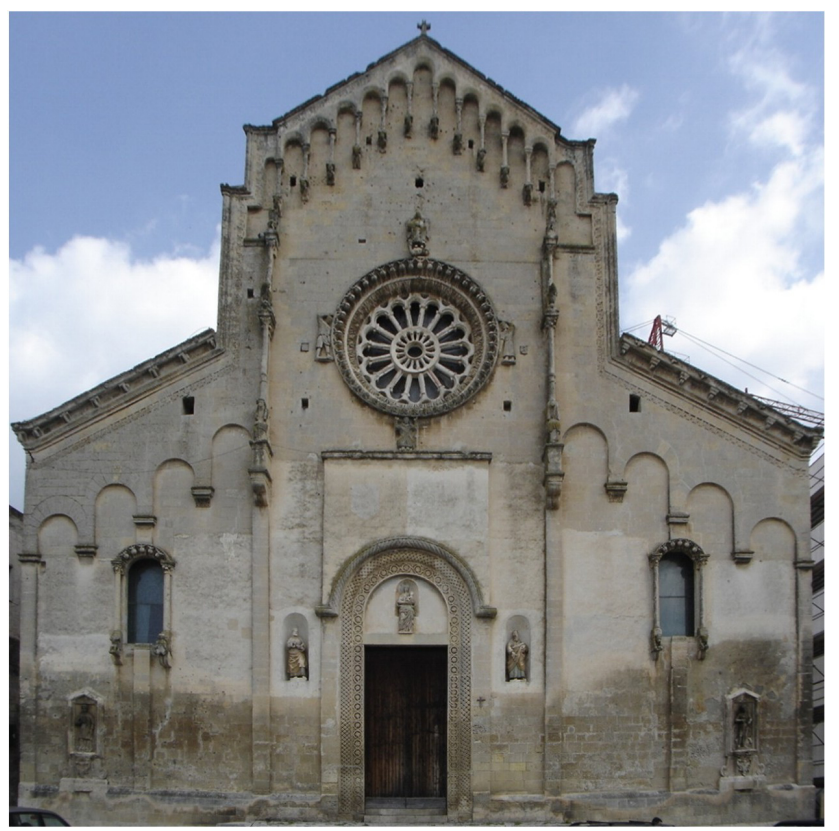

Fig. 1. The cathedral of Matera.

\section{The case history of the Cathedral of Matera}

The Cathedral of Matera (Fig. 1) is one of the most remarkable witnesses of the so-called "Romanico Pugliese", that is a kind of Romanesque style spread in the Apulia region and in other neighbouring areas. It is located on a panoramic spur facing the famous "Sassi" of Matera, included in the World Heritage.

The church has a Latin Cross plan, composed of three longitudinal aisles cut transversally by a transept. It was built between 1230 and 1270, on two pre-existent crypts and the foundations of a church dedicated to St. Eustachio

Most of the external structures preserves its original Romanesque characteristics, but the inner of the church appears instead modified by successive changes, as the central nave, mostly ascribable to the 17 th century. However, some more ancient details dating back to the first half of the 13th century still remain also inside the church, as for instance a rich variety of capitals of different shapes (leafs, crowns, anthropomorphic and zoomorphic motifs).

Currently the Cathedral is under restoration. The works are prevailingly aimed at the structural rehabilitation of pillars, columns, walls and roofing.

In particular, it is worth to quote some vertical and subvertical cracks which affect two polystyle pillars of the triumphal arch of the choir. They could be the effect of a deflection phenomenon to which Superintendance of Architectural Heritage of Basilicata tried to find a structural solution in the restorations carried out in 1989. Each polystyle pillars is composed of a square element, with three semicolumns and four pilasters, on its sides. They are constructed in masonry, in its turn composed by calcarenite ashlars and a central nucleus filled with incoherent material of calcarenite nature and dark soil, as shown by some core tests made during the 1989 restorations.

Another instability phenomenon affects one of the monolithic columns. It is composed by dense limestone and is affected by some cracks on the basement, as well.

In order to investigate both the state of conservation of building elements and the possible presence of previous remains, the Superintendance of Architectural Heritage of Basilicata has commissioned a geophysical prospecting campaign to the Institute for Cultural Heritage and Monuments of the National Research Council (IBAM-CNR). It has been thought of to perform a GPR prospecting on the floor, in the central nave and the accessible areas of the lateral naves, which are partially filled with scaffoldings.

In fact, the flat surface of the floor and the presumably quite dry underground (together with the kind of target looked for) made a GPR prospecting the most promising on the soil.

For the study of the two pillars GPR investigations have been performed, whereas for the column GPR and ultrasonic tests have been compared in order to have more data for the diagnosis.

\section{Investigations carried out: data acquisition, process- ing and results}

The GPR prospecting has been performed making use of the collaboration and the instruments of the Centro di Competenza Innova of the Campania Region. The GPR was a SIR3000 equipped with four linearly polarized antennas, with nominal central frequency of $150,400,600 \mathrm{MHz}$ with regard to the prospecting on the floor (however, the most clear results have been obtained from the antennas at $400 \mathrm{MHz}$ ) and $1000 \mathrm{MHz}$ for the prospecting on the pillars.

The ultrasonic tests have been performed by using a pulse generator MAE A5000U, equipped with a contact probe with frequency of $55 \mathrm{KHz}$.

A multifrequency approach by using only the GPR has been adopted for the investigations performed on the floor, whereas GPR data acquired with the antenna at $1000 \mathrm{MHz}$ have been exploited for the analysis of some masonry pillars.

Finally for the analysis of the monolithic column, the GPR high frequency scans have been compared with ultrasonic tests, as will be shown.

Also a more refined diagnostic technique has been exploited to process the data. In particular, some data have been elaborated by means of a linear inverse scattering algorithm based on a 2-D scalar model in frequency domain. A technical exposition of the technique would require some space and so it is avoided here. However, this algorithm has been exploited for years, and the interested reader can find details in (Persico, 2006; Persico, 2007; Persico and Sol- 



Fig. 2. (A) Radar scans near the altar, focalised by means of a linear inverse scattering algorithm; (B) Raw data relative to the images of Fig. 2A.

dovieri, 2008) and references therein. Here, we just limit to say that this technique allows to get a reliable focalisation of the targets together with a stable result theoretically accounting for the losses in the soil. The most meaningful result have been obtained near the altar (just up the upper limit of the image on the left hand side), and are shown in Fig. 2A. In order to deliver the insight specifically provided by the processing, let us specify that the zone near the altar relative to the scans of Fig. 2A was filled with a metallic scaffolding for the restoration. We think that the mutual distances and the periodicity of the "point-like" scattering targets put into evidence by Fig. 2A are due to the metallic scaffolding, or at least the scaffolding affects meaningfully the results. For the inversion of Fig. 2A, a frequency step of $20 \mathrm{MHz}$ has been exploited and the data have been decimated so to exploit a spatial step of $4 \mathrm{~cm}$. The relative permittivity of the soil has been evaluated equal to 5 , based on the available a-priori information, and a small conductivity of $0.005 \mathrm{~S} / \mathrm{m}$ has been assumed. The exploited band for the inversion was $200-600 \mathrm{MHz}$, based on the spectra of the data. Let us outline that the raw data (shown in Fig. 2B don't allow to clue such a feature, that is therefore made much more clear by the focussing procedure.

The most interesting results achieved from the subsoil investigation are well resumed by the slice in Fig. 3. The horizontal slice has been obtained from B scans with the antennas at $400 \mathrm{MHz}$. The scans were parallel to the central nave with regards to the lower part of the figure, but they were orthogonal to the central nave with regard to the upper part of Fig. 3. The scans have been taken in continuous mode and at the distance between any scan line and the next one was $50 \mathrm{~cm}$. The time-depth conversion have been performed accounting for a relative permittivity of the soil equal to 5, retrieved as a-priori information from the fact that we have been said that that the soil underlying the church was essentially constituted

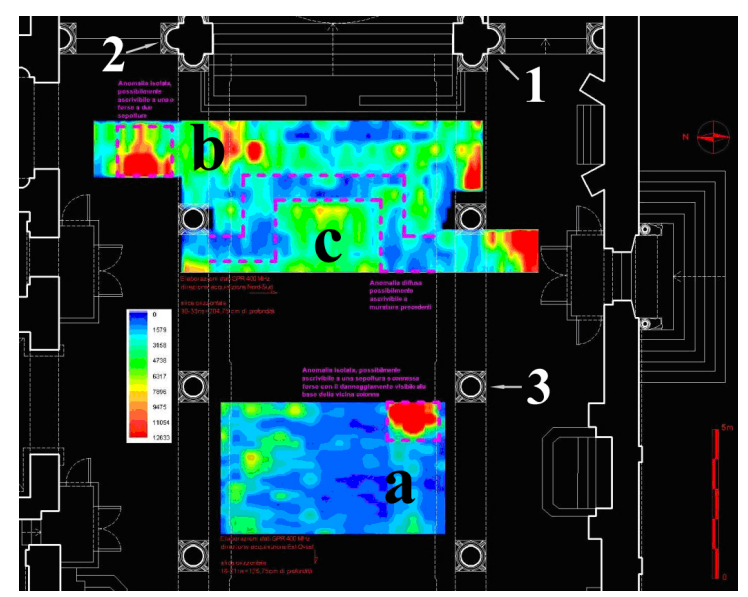

Fig. 3. Horizontal GPR slice at about the depth of $0.8 \mathrm{~m}$. The letters "a" and "b" denote the presence of anomalies which could be related to tombs., whereas the letter "c" indicates anomalies which could be connected to buried masonry structures.

by calcarenite (there was no possibility to perform excavation tests). The features put into evidence from Fig. 3 are confirmed also by several further horizontal slices not shown here for sake of brevity. Near the second column on the right hand side of the central nave, at the depth of 60 up to $120 \mathrm{~cm}$ a strong anomaly is evident (see "a" in Fig. 3). It may correspond to a void related to a tomb. This anomaly is particularly important, because the basis of the column near it is fractured, and this might be connected with the subsidence corresponding to the anomaly. Another anomaly on the left nave ("b", Fig. 3) may be another tomb.

Anomalies of possible archaeological interest are between the first and the second span, from the altar, at the depth of 80 up to $150 \mathrm{~cm}$. In particular, the slice ("c" Fig. 3) puts into evidence anomalies oriented according a " $\pi$ " shape. If 




Fig. 4. Right-hand pillar: the radargrams in $\mathrm{X}$ and $\mathrm{Y}$ direction and their interpretation.

it were related to masonry structures it would suggest and $\mathrm{s}$ square apse. The existence of a previous church, known by the documents, makes this anomaly worth to be considered for future archaeological trials.

Let us now pass to the GPR scans performed on building elements (pillars and columns). As said, these have been obtained with the $1000 \mathrm{MHz}$ antenna, whose band (evaluated from the data) was about extended from 800 to $1600 \mathrm{MHz}$.

Figure 4, show the radargrams acquired along the $\mathrm{X}$ and $\mathrm{Y}$ directions on the right pillar of the triumphal arch (the scales are in metres). Under the radargrams, we have find useful to show also the arithmetic average of all the radar traces. The interpretation has been made easier by the information derived by some core test performed in 1989. This allows to know that the inner structure is like that shown in Fig. 5.

The scans 1-49, in $\mathrm{X}$ direction, put in evidence six vertical reflections (B1, B2, B3, C1, C2, C3 in Fig. 4): some related to interfaces between different materials, other interpretable as material discontinuities (e.g. ashlars joints or cracks).

In particular, both $\mathrm{C} 3$ and $\mathrm{C} 2$ could be interpreted as lack of connection between ashlars respectively of semicolumn and pilaster, and pilaster and square pillar. Whereas $\mathrm{C} 1$ and B2 may be related to interfaces between calcarenite blocks and incoherent soil, and B3 suggests the presence of an ashlars joint. Finally it is worth to mention a single and clear hyperbola near the left semicolumn. It may be caused by as 

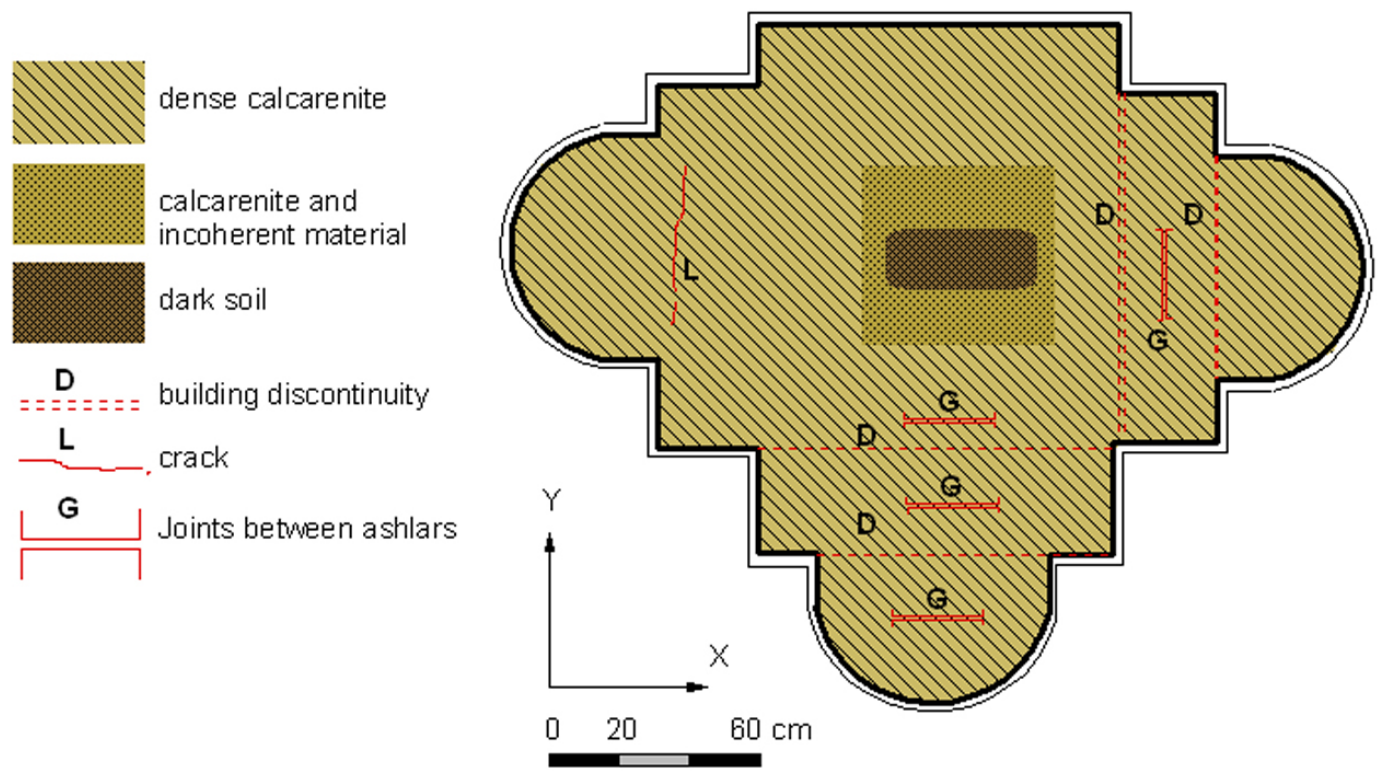

Fig. 5. Right-hand pillar: inner structure of the pillar.
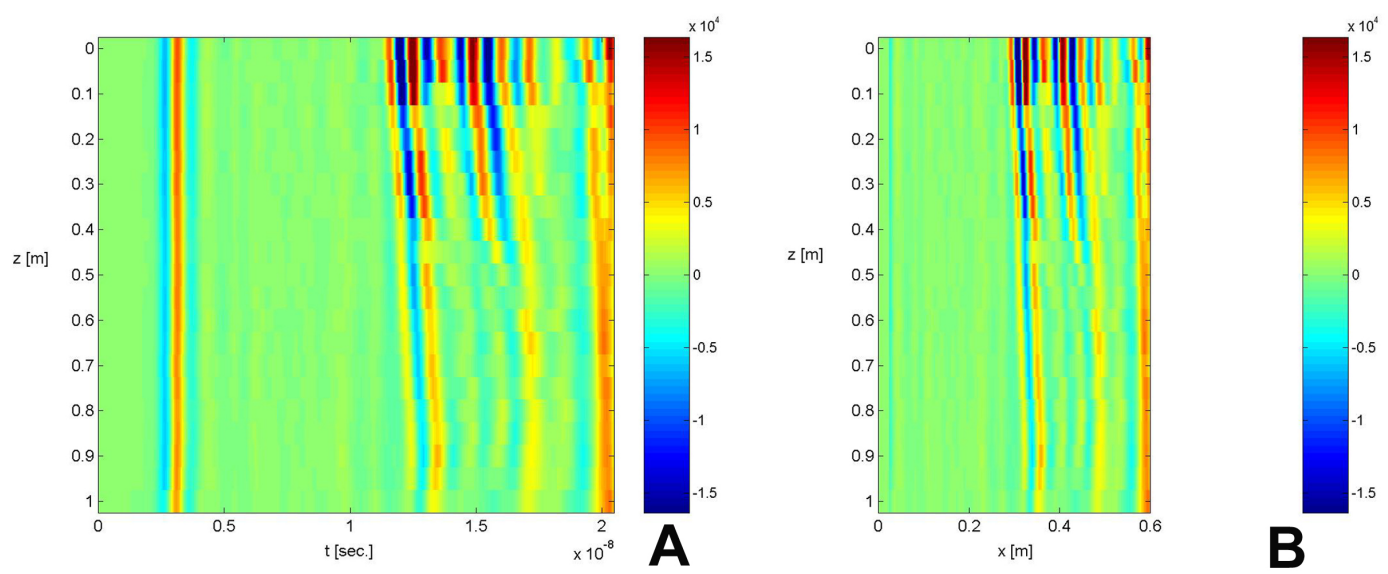

Fig. 6. Radar scan on the monolithic column. Right-hand panel: raw data (the time is in seconds). Left-hand panel: the data after interface cancellation and time-depth conversion (the depth is in meters).

shapeless stone material (rubble) as a fracture. This would be also coherent with some cracks clearly visible on the surface of the semicolumn.

The scans 50-89, in $\mathrm{Y}$ direction, show an area characterized by some hyperbolas (A) and six vertical reflections (B1, B2, B3, C1, C2, C3). The hyperbolas are of difficult interpretation. They may be related as to shapeless materials as metallic bars with strengthening function inserted during the restoration occurred in 1989.

As regards the reflections, it is reasonable to attribute them either to interfaces between different materials (B1), or to joints between calcarenite ashlars (see B2 and B3 in Figs. 4 and 5).
The GPR prospecting carried out on the left-hand pillar allowed (as in the case of the right-hand pillar) to characterize its inner structure and to detect joints and cracks, as well. Further details are not shown here for sake of brevity.

Finally, the scans performed on the monolithic column (the third on the right side of the central nave), put in evidence at heights between 50 and $100 \mathrm{~cm}$ from the roof, significant reflections, which may be connected as to fractures as to lithological interfaces (Fig. 6). Let us remind that the base of the column is affected by cracks.

Therefore, in case of fracture we would be in presence of a serious structural instability. In order to investigate this fundamental question, ultrasonic tests have been performed at the heights of 65,100 and $145 \mathrm{~cm}$. The frequency used 


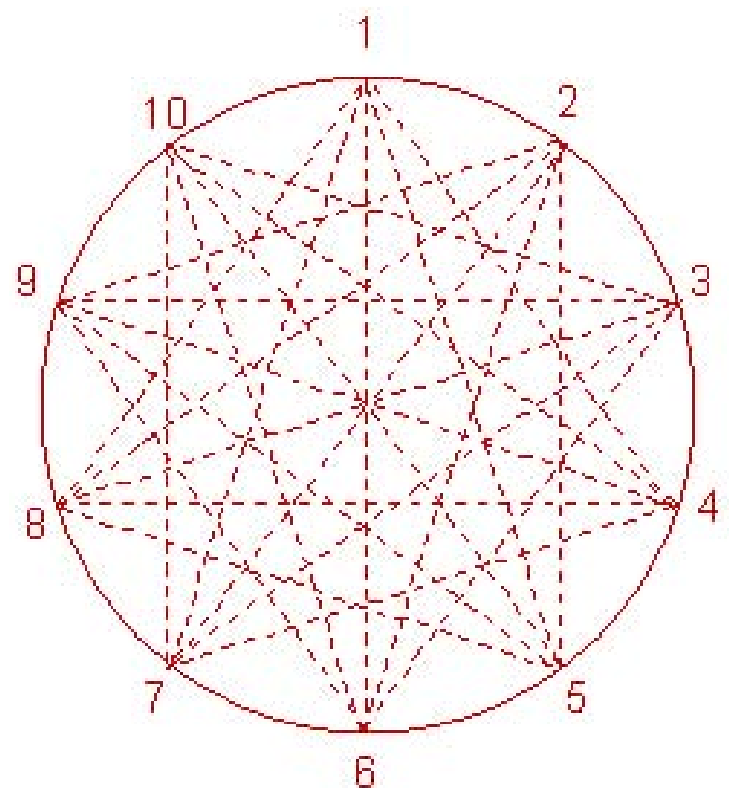

Fig. 7. Scheme of the measurement points for the ultrasonic tomography of a section of the column.

for the longitudinal velocity measurements was $55 \mathrm{KHz}$, in transmission mode. For each velocity measure, opposite points on the column have been taken, according the scheme shown in the Fig. 7. By means of an home made software, the measured velocities have been processed in order to obtain tomographies (Fig. 8).

As shown in Fig. 8, the tomographies do not put in evidence either significant variations in velocity or alignments of points with low value velocity which might be related to cracks. Therefore, it is more reasonable to interpret the anomalies observed in the radargrams as lithological interfaces.

\section{Conclusions}

A multifrequency and multisensor approach proved to be reliable for the inspection of the subsoil and load bearing structures of a monument, in order to support intervention strategies of rehabilitation and to provide useful information for future archaeological investigations.

In particular, GPR prospecting with medium frequency antenna allowed to detect buries structures likely to be of archaeological interest.

Moreover, the identification of a void near a column affected by cracks on the base make necessary to proceed in the investigations, in order evaluate its role in the instability

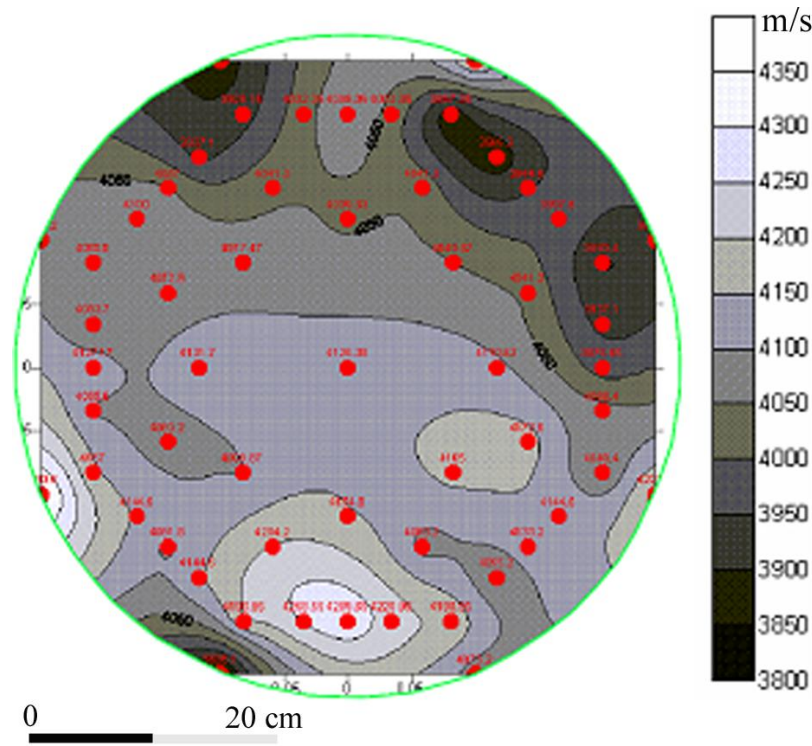

Fig. 8. Ultrasonic tomography performed on a section of the column at height of $65 \mathrm{~cm}$.

phenomenon. With regard to this point, let us remind that the integration of ultrasonic tests and GPR prospecting with high frequency antenna seem to exclude a structural yielding. This leans towards a foundation yielding as cause of the cracks on the base of the column.

Finally, the high frequency GPR scans provided with a resolution sufficient to characterize building elements and to detect discontinuities and cracks.

Edited by: F. Soldovieri

Reviewed by: two anonymous referees

\section{References}

Binda, L., Saisia, A., Tiraboschi, C., Valle, S., Colla, C., and Forde, M.: Application of sonic and radar tests on the piers and walls of the Cathedral of Noto, Constr. Build Mater, 17(8), 613-627, 2003.

Masini, N., Nuzzo, L., Rizzo, E.: GPR investigations for the study and the restoration of the Rose Window of Troia Cathedral (Southern Italy), Near Surf. Geophys., 287-300, 2007.

Persico, R.: On the role of measurement Configuration in Contactless GPR data Processing by Means of Linear Inverse Scattering, IEEE Trans, On Antennas and Prop AP, 54(7), 2062-2071, July 2006.

Persico, R.: "Paralipomena" on uniqueness in inverse scattering from a finite number of data, Ann. Geophys., 50, 165-175, 2007, http://www.ann-geophys.net/50/165/2007/.

Persico, R. and Soldovieri, F.: Effects of the Background Removal in Linear Inverse Scattering, IEEE Trans. Geosci. Remote Sens., 46(4), 1104-1114, 2008. 